\title{
Solar Energy as Expedient Alternatives for Nuclear Energy
}

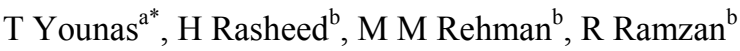 \\ ${ }^{\mathrm{e}}$ Assistant Professor, Szabist, Karachi and 75600, Pakistan \\ ${ }^{\mathrm{b}}$ Student, Szabist, Karachi and 75600, Pakistan
}

\begin{abstract}
The development of solar power technologies is considered to be the key solutions for fulfilling ever increasing worldwide demand for energy. This paper reflects the nature, characteristics, similarities, and differences between nuclear and solar energies. It also discusses their technologies, their impact on different aspects of life and public attitudes about them. Generally, nuclear energy is considered to be destroyed due to uncontrollable chemical reactions associated with harvesting of nuclear energy. Energy requirement of the world is increasing day by day, and using conventional methods to fulfil this requirement might cause devastating effects on atmosphere due to an emission of different harmful by-products released. In this paper, alternate methods of producing energy are discussed and a detailed analysis of its environmental effects, sustainability and cost have been discussed.
\end{abstract}

\section{Introduction}

An Energy crisis is one of the big problems of the world nowadays. There are as many as ten main resources of energy which are being used in the different part of the world. We would be discussing and comparing only two of them i-e Nuclear energy and Solar energy. First, we need to understand what nuclear energy is. According to Einstein's equation it is described below:

$$
E=m c^{2}
$$

Mass (m) can be converted into energy (E) in nuclear process. In the equation, $\mathrm{c}$ is speed of light. Therefore, the more mass has we used the more energy we produce [1]. We cannot see an atom and its sub-particles with our open eyes because they are too small, so their counting is not possible. However, scientists (particularly physicists and chemists) have been studying atoms for over 200 years and have developed models to explain the results of their experiments.

In our solar system, the sun is the only star which is stationary and all planets including the Earth are rotating around it. All life on Earth is supported by the energy in the form of solar radiation gathered from the sun. It is done through the system known as photosynthesis. It also controls the climate and weather of the Earth [2]. The energy requirements of the entire world for a full year can be met by the sunlight coming to Earth in an hour and a half [3]. Solar energy is the oldest energy source ever used. Solar power is an ideal power source we can capture with solar panels and other collectors. Once these collectors are manufactured, there is no pollution or waste product. At the same time, there are no moving parts to hurt wildlife. Solar energy has the potential to full fill the energy demands of the entire world if technologies for its harvesting and supplies or made available [4]. Adoption of solar technologies would be mitigated all issues connected with energy security, climate change, and unemployment. It will also play an important role in transportation sector because it does not require any fuel transportation. The annual solar distribution over the Earth surface is shown in figure 1.

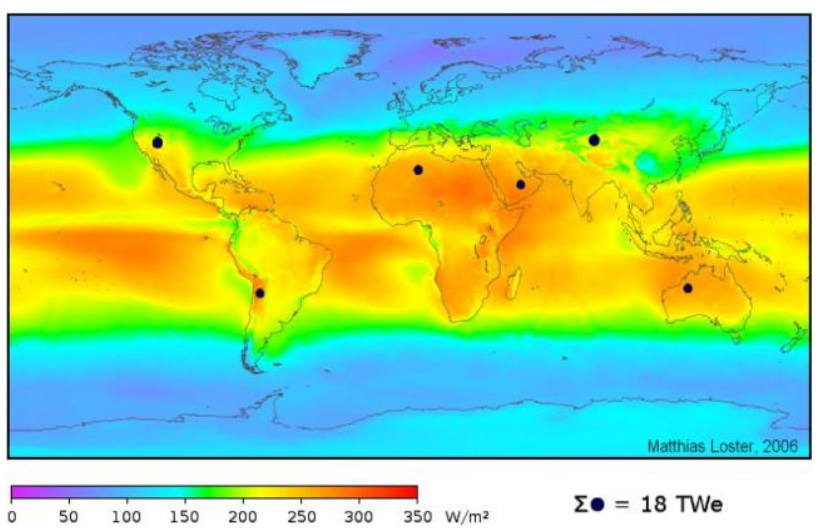

Figure 1. Annual average solar distribution [5].

\section{Comparison between nuclear and solar energies}

\subsection{Status of technologies}

Nuclear power generation system comprises the nuclear reactor and its energy conversion system. To achieve the aims of generation system, four areas are required to develop and these are:

*Corresponding author: Tanzila@szabist.edu.pk 
1. Sustainability

2. Safety and reliability

3. Proliferation resistance

4. Physical protection and economies

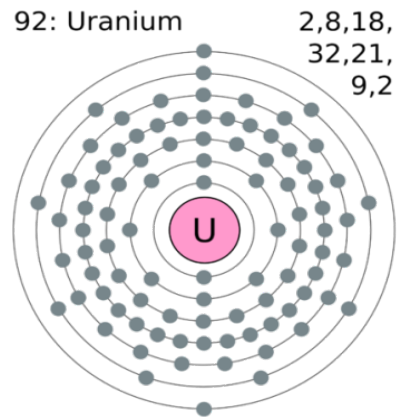

Figure 2. Uranium Model [6].

Uranium model shown in figure 2 tells us that nuclei are continuously breaking up and throwing out neutrons. Experiments show that if a neutron hits or is absorbed in the nucleus of another uranium atom, the nucleus may split into two parts and releases two or three neutrons and give off energy. This process is called "fission" and the energy is called "nuclear" energy. The fission reaction is shown in figure 3

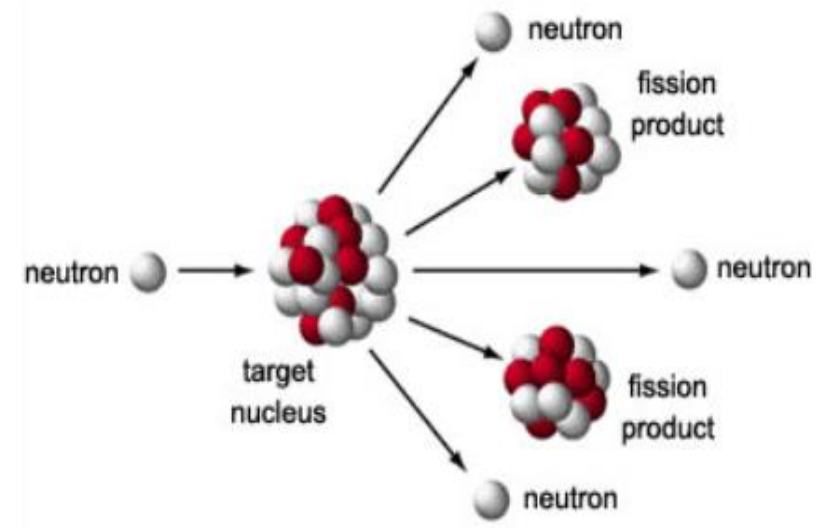

Figure 3. Fission Reaction [7].

An active solar system collects solar radiation and uses mechanical and electrical equipment for conversion of solar energy to heat and electric power. The most popular application of the system is solar water heater system.

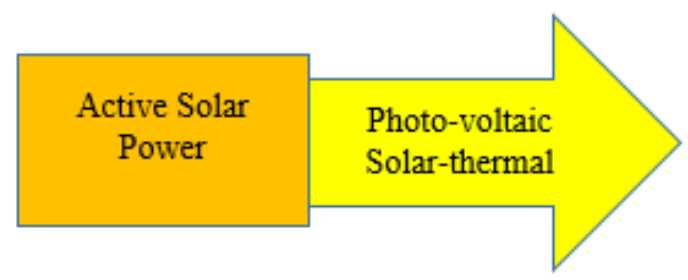

Figure 4. Classification of Active Solar Power.

There are two kinds of active solar energy technology as shown in figure 4. One is photo-voltaic technology, and the other is thermal technology. In photo-voltaic technology semiconductors are used to convert sunlight directly into electric energy. Whereas in thermal technology, solar energy is harnessed into thermal energy for domestic as well as commercial application such as drying, heating, cooling, cooking, etc. Concentrating solar power (CSP) is typically used electricity plants and is not beneficial for the residential purpose. This technology makes use of mirrors to reflect and concentrate sunlight onto receivers that collect solar energy and convert it into warmth that could later be used to provide electricity [8]. The critical raw material of solar energy technologies is shown in the table 1 .

Table 1. Critical Raw Materials Content. [9].

\begin{tabular}{|c|c|c|}
\hline Application & Components & $\begin{array}{c}\text { Critical raw } \\
\text { materials }\end{array}$ \\
\hline $\begin{array}{c}\text { Photo-voltaic } \\
\text { and Thermal }\end{array}$ & $\begin{array}{c}\text { Semi- } \\
\text { conductor } \\
\text { Indium, Gallium, } \\
\text { Germanium } \\
\text { Selenium, } \\
\text { Tellurium }\end{array}$ \\
\hline $\begin{array}{c}\text { Concentrating } \\
\text { solar power } \\
\text { (CSP) }\end{array}$ & $\begin{array}{c}\text { Electric } \\
\text { contacts } \\
\text { mirror }\end{array}$ & Silver \\
\hline
\end{tabular}

\subsection{Public Support}

It is very interesting to note the public opinion differs from time to time for support or rejection of any energy sources. Following table shows that as much as $90 \%$ public support is in favour of solar power energy. Whereas $38 \%$ support is enjoyed by nuclear energy. The public support for various energies is shown in the table 2 and figure 5 .

Table 2. Public support in percentage for various energies [10].

\begin{tabular}{|c|c|}
\hline $\begin{array}{l}\text { Energy } \\
\text { resources }\end{array}$ & $\begin{array}{l}\text { Public support } \\
(\%)\end{array}$ \\
\hline Solar power & 97 \\
\hline Wind power & 93 \\
\hline $\begin{array}{l}\text { Hydroelectric } \\
\text { power }\end{array}$ & 91 \\
\hline Natural gas & 80 \\
\hline Coal & 48 \\
\hline Nuclear energy & 38 \\
\hline
\end{tabular}




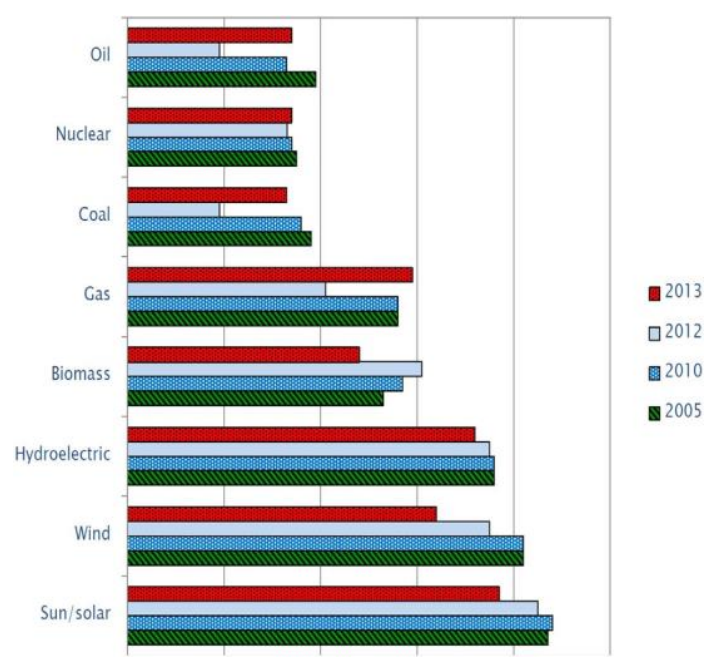

Figure 5. Changing attitudes to popular support for various technologies [11].

\subsection{Accidents}

In this section, we will describe serious incident and accidents at nuclear power stations. Since first of its kind occur in 1952in Canada [12]. We have identified 33 incidents and accidents from 1952 to date. In fact, international atomic energy authority does not have a complete historical database of such incidents and accidents. Out of 33, six had happened in the US, five in Japan and UK and Russia have had three. International atomic energy authority ranks these incidents and accidents using a special international nuclear scale ranging from anomaly to major accidents and has numbered them from one to seven. There has been only one scale seven incident in history at Chernobyl in 1886 [13]. The events at Fukushima were level five only. Placing solar panels on roof is quite dangerous only in Australia about 30 people died every year due to falling from height during installing solar panels. However solar panel may ultimately be safer than other energy resources because of the reduction of pollution and putting solar panel on ground.

\section{Application of solar energy}

Considering the usage of energy and energy requirements, a lot of people are considering it to be the alternate energy source. Considering eco-friendly nature of solar energy, solar energy has a great number of applications. These applications have a wide spectrum from industrial to domestic use. From wide range, some of the applications are discussed in this paper [14].

\subsection{Solar water heating}

Solar water heating unit consist of blackened flat plate metal collector with an associated metal tubing generally facing toward the sun. A layer of transparent glass and insulation is placed between metal tubing.

\subsection{Solar distillation}

In remote areas, clean water is one of the major issues. A solar distillation plant can be installed in remote and arid areas and this issues can be resolved. This solar distillation process works on the principle of absorption of solar radiation. These radiations are converted into heat and through this heat water is evaporated. This evaporated water is potable and is collected in a collection unit of the plant.

\subsection{Solar furnaces}

Solar furnaces can be used for processes that require high temperature. It uses a number of rotate-able mirrors which can be used to focus the solar beams. By adjusting mirrors, solar beams can be focused at a single point and can cause a high temperature

\subsection{Solar electric power production}

In Photo-voltaic cells are used for direct production of electricity. These photo voltaic cells are made of semiconductors releases electrons when photons strike on the photo voltaic cells. These cells are arranged in series or parallel combination to form modules. These electric power stations vary in sizes according to the usage. These units can be used in powering up street lights as well as charging batteries in satellites

\subsection{Solar green house}

Solar greenhouse consists of large transparent structures that acts as a solar cell. Energy collected through this process can be used to produce heat for growing plants. As the radiations trapped in the house cannot escape, air inside the greenhouse gets enriched with $\mathrm{CO} 2$ which helps in better growth of plants.

\section{Discussion}

Nuclear power plants rely on uranium mining or processing which makes it non-renewable energy whereas renewable solar power generate utilizes sunlight which makes it renewable one. Nuclear energy does not emit greenhouse gasses directly but nuclear fuel cycle produces them indirectly. As solar energy does not contain any element, it is considered clean and environmentally friendly source of energy. Nuclear power is a high risk because of the chemicals in it. It can destroy the whole earth due to the radiation in it. Nuclear energy installation process is not very common so this type of energy is not available to everyone. Whereas solar energy simple in nature can be available to everyone. 


\section{Conclusion}

We can easily conclude that solar energy does not only need of the hour but also need of the future because of its pollution-free nature, safety, and convenience. Solar energy has wider usage in all fields of society and is one of the energies consider as infinite for humankind. Solar energy is available even outside the solar system whereas it is not so with nuclear energy. We can easily say that solar energy will develop well and become far more pollution-free than now. Both these energies have low greenhouse gas emissions and high-cost electricity. They still differ in many ways like safety and principle of operation of devices It is obvious that the application of nuclear and solar energy will grow in future but solar energy is more promising.

\section{References}

1. The physics of the universe. [Online]. Available: http://www.physicsoftheuniverse.com/topics_relativi ty_emc 2 .html

2. Space based solar power [Online]. Available: https://en.wikipedia.org/wiki/Spacebased_solar_power

3. Solar energy technology basis, August 16, 2013 [Online]. Available: https://energy.gov/eere/energybasics/articles/solarenergy-technology-basics

4. Conserve Energy Future [Online]. Available: https://www.conserve-energy-

future.com/alternativeenergysources.php

5. Renewable and nuclear electricity: Comparison of environmental impacts Energy Policy, Volume 96, September 2016, Pages 758-769 by Charles McCombie, Michael Jefferson

6. [Uranium model [Online] Available: https://www.quora.com/Is-uranium-
$\% \mathrm{E} 2 \% 80 \% 9 \mathrm{C}-92-\% \mathrm{E} 2 \% 80 \% 9 \mathrm{D}$-possible-uraniumnucleus-without-electrons-e-g-through-ionisation

7. Nuclear fission [Online] Available: $\mathrm{http}: / / \mathrm{www}$.atomicarchive.com/Fission/Fission1.sht $\mathrm{ml}$

8. Concentrating Solar Power Basics, August 20, 2013

[Online]

Available :

https://www.energy.gov/eere/solar/articles/concentrat ing-solar-power-basics

9. Edenhofer, O., et al., 2011. Renewable Energy Sources and Climate Change Mitigation: Special Report of the Intergovernmental Panel on Climate Change. Cambridge University Press, Cambridge

10. Wallard, H., Duffy, B, Cornick, P., 2012. After FukushimaI, Global Opinion on Energy Policy, IPSOS Social

11. Solar energy: Potential and future prospects Renewable and Sustainable Energy Reviews, Volume 82, Part 1, February 2018, Pages 894-900 by Ehsanul Kabir, Pawan Kumar, Sandeep Kumar, Adedeji A. Adelodun, Ki-Hyun Kim

12. Nuclear power plant accidents [Online] Available: https://www.theguardian.com/news/datablog/2011/m ar/14/nuclear-power-plant-accidents-list-rank

13. Green deaths: The forgotten dangers of solar panels by Gavin Atkins, 17 May 2011 [Online] Available: https://asiancorrespondent.com/2011/05/greendeaths-the-forgotten-dangers-of-solar-panels

14. Solar Energy: Major Application of Solar Energy Article shared by : Puja Mondal [Online] Available: http://www.yourarticlelibrary.com/energy/solarenergy-10-major-application-of-solar-energyexplained/28197 